\title{
Los mecanismos del imperialismo canadiense en el sector minero de América Latina
}

\author{
Darcy Tetreault
}

RESUMEN. Los mecanismos empleados por el gobierno canadiense para ayudar a las compañías mineras canadienses a ganar acceso a los recursos minerales y la fuerza de trabajo barata en América Latina incluyen el impulsar reformas neoliberales, intervenir en la reformulación de la legislación minera, subregular la Bolsa de Valores de Toronto, brindar beneficios impositivos, subsidios directos y apoyo diplomático a las compañías mineras canadienses operando en el extranjero, y rehusar a regularlas fuera del país. Si bien estos mecanismos no constituyen por sí mismos el imperialismo, se argumenta que reflejan las estrategias imperialistas de una potencia media que ha ayudado a moldear la evolución del sistema capitalista global hacia los principios del comercio libre, privatización y desregulación. De esta manera, el capital minero canadiense ha podido externalizar costos.

PALABRAS CLAVE: imperialismo canadiense, minería, acumulación por desposesión.

Aвstract. The mechanisms employed by the Canadian government to help Canadian-based mining companies gain access to the mineral resources and cheap labour force in Latin America include pushing for neoliberal reforms, intervening in the rewriting of mining legislation, under-regulating the Toronto Stock Exchange, providing tax benefits, direct subsidies and diplomatic support to Canadian mining companies operating abroad, and refusing to regulate them outside of the country. While these mechanisms do not in and of themselves constitute imperialism, this article argues that they reflect the imperialist strategies of a middle power that has helped to shape the evolution of the global capitalist system towards the principles of free trade, privatization and deregulation. Along these lines, Canadian mining capital has been able to take advantage of the lax environmental and labour standards that exist in Latin American in order to externalize costs.

KEYWORDS: canadian imperialism, mining, accumulation by dispossession.

Darcy Tetreault es profesor-investigador de la Unidad Académica de Estudios del Desarrollo de la Universidad Autónoma de Zacatecas, México. 


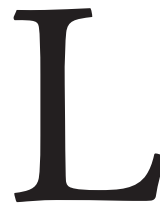
as compañías mineras canadienses dominan el sector minero a escala mundial. De hecho, tres cuartas partes de las empresas mineras en el mundo tienen sus oficinas centrales en Canadá y casi $60 \%$ están registradas en la Bolsa de Valores de Toronto. Estas compañías representan cerca de $40 \%$ de la inversión mundial en exploración minera en el mundo, con 1,817 proyectos en América Latina y el Caribe (Mining Association of Canada, 2011: 48). América Latina destaca como principal región por la que opta la inversión minera canadiense, quedando África muy atrás en segundo lugar. En efecto, más de la mitad de los activos de las mineras canadienses se ubica en América Latina, con un valor estimado de aproximadamente 57 mil millones de dólares (Keenan, 2010). Compañías como Barrick Gold, Yamana Gold, Goldcorp, Teck, Kinross Gold y Pan American Silver llevan la delantera, cada una de ellas con ingresos anuales por encima de mil millones de dólares por concepto de operaciones en América Latina (CIDP, s/f).

¿Cómo es que las compañías mineras canadienses llegaron a dominar el sector? La primera sección de este artículo resume cómo el gobierno canadiense ha fomentado al capital minero hasta llegar a su posición de dominio mundial, enfocándose en América Latina. En la segunda sección, esta proyección del poder del Estado se contextualiza en un breve análisis de los debates en torno al imperialismo contemporáneo. El principal argumento es que, en la era neoliberal, Canadá ha surgido como una potencia media imperialista. Esto lo evidencia la manera en cómo el gobierno federal recurre al ingreso público y políticas públicas para promover los intereses del capital minero canadiense, allanando el camino de su expansión en América Latina y otras regiones. Debido a que el gobierno canadiense no obliga a las compañías mineras canadienses a tomar responsabilidad por sus acciones en el extranjero, éstas pueden aprovecharse de la laxitud de las normas ambientales y laborales en los países latinoamericanos, externalizando así los costos ambientales y sociales de sus actividades extractivas. La población que paga la mayor parte de estos costos son los campesinos y grupos indígenas que habitan en las zonas próximas a las operaciones mineras. Son éstas las poblaciones desposeídas de las 
tierras, las fuentes de agua y los paisajes culturales que sostienen sus medios de vida. De esta forma, la rentabilidad de las compañías mineras canadienses forma parte de un proceso más general de «acumulación por desposesión», mediante el cual los recursos y la población que se encuentran fuera de la lógica estricta del capitalismo son jaladas a su órbita como parte del proceso de globalización neoliberal.

\section{LA AgENCIA DE UNA POTENCIA IMPERIALISTA MEDIA}

La mayor parte de los trabajos recientes que aborda «el nuevo imperialismo», particularmente desde inicios del siglo xxi, se ha centrado en el papel que desempeña Estados Unidos como única súper potencia, al recurrir a su poder militar, político y económico para reestructurar la economía mundial, de tal manera que le permita mantener su hegemonía (por ejemplo: Foster, 2003; Harvey, 2004; Panitch y Gindin, 2003; Wood, 2003) o, de acuerdo con algunos observadores (especialmente Robinson, 2008, 2010), para proyectar los intereses de una clase capitalista trasnacional amorfa. No obstante, recientemente se han publicado varios estudios destacados que abordan el tema del imperialismo canadiense, entre ellos los de McNally (2006), Gordon y Webber (2008), Gordon (2010) y Denault y Sacher (2012). Estos trabajos pintan una imagen de Canadá como una potencia imperialista media que no sólo adoptó la agenda neoliberal sino que ha contribuido a impulsarla, al fomentar el ajuste estructural y moldear acuerdos comerciales conforme a los intereses de las grandes empresas canadienses. En todos estos trabajos, el sector minero desempeña un papel toral para ilustrar la orientación imperialista del Estado canadiense. Con base en estos estudios y otros trabajos de investigación, en esta sección se destilan los mecanismos del imperialismo canadiense en el sector minero de América Latina, sistematizándolos en torno a siete temas. 


\title{
Promoción de
}

las reformas neoliberales

En términos generales, desde finales de los años ochenta, el gobierno canadiense (bajo el control del Partido Liberal, al igual que el Partido Conservador Progresista) ha promovido el ajuste estructural neoliberal, poniendo la mira en conseguir oportunidades de inversión para el capital canadiense en el Sur global. Como Gordon hace notar:

\begin{abstract}
La Agencia Canadiense de Desarrollo Internacional [Canadian International Development Agency, CIDA] y las Secretarías de Finanzas [Department of Finance] y de Relaciones con el Exterior [Department of Foreign Affairs] respaldaron y promovieron decididamente el ajuste estructural como parte de un esfuerzo para facilitar la expansión de los intereses económicos canadienses inmediatamente después de la reducción del margen de rentabilidad de los años de 1970 y 1980 (Gordon, 2010: 142).
\end{abstract}

CIDA ha condicionado su ayuda para el desarrollo a la adopción de reformas neoliberales en los países receptores, mientras que la Secretaría de Finanzas respaldó los programas de ajuste estructural promovidos por el Banco Mundial y el Fondo Monetario Internacional (FMI). Además, desde inicios de los años noventa, el gobierno canadiense ha negociado y entrado en varios acuerdos comerciales multilaterales y bilaterales que incluyen medidas para proteger las inversiones canadienses en el extranjero. El capítulo 11 del Tratado de Libre Comercio de América del Norte (TLCAN) es un ejemplo, en la medida que otorga a las empresas extranjeras el derecho de entablar demandas contra los gobiernos anfitriones por cualquier política pública o acción que les niegue oportunidades de inversión u obtención de beneficios. En el mismo espíritu, entre 1991 y 2012, Canadá firmó 32 Acuerdos de Promo- 
ción y Protección de la Inversión Extranjera (FIPA, por sus siglas en inglés), entre ellos nueve en América Latina y el Caribe, con el fin de asegurar que las empresas canadienses reciban el mismo trato que las empresas nacionales y darles el poder legal de demandar a los gobiernos anfitriones cuando tomen decisiones que ponen en riesgo la capacidad de las empresas canadienses de maximizar sus ganancias.

Incluso donde no existen estos acuerdos, las compañías mineras canadienses pueden aprovecharse, y de hecho lo hacen, de otros marcos normativos internacionales que han sido establecidos como parte de la agenda neoliberal más amplia para favorecer al capital transnacional. Éste es el caso de Pacific Rim, una compañía minera canadiense que interpuso un juicio contra el gobierno salvadoreño en 2008, por atender a los reclamos de un movimiento local que se opuso a las actividades mineras propuestas. De acuerdo con los representantes legales de Pacific Rim, la negación de un permiso para extraer minerales constituye una violación al Tratado de Libre Comercio con Centroamérica (CAFTA, por sus siglas en inglés). Sin embargo, debido a que Canadá no forma parte de dicho acuerdo, la empresa tomó acciones legales a través de su subsidiaria estadounidense, Pacific Rim Cayman, que fue trasladada de las Islas Caimán a Nevada en diciembre de 2007.

\section{Intervención directa en la administración}

del sector minero en los países de América Latina

El gobierno canadiense también ha intervenido directamente en la reformulación de la legislación y en la administración del sector minero en algunos países de América Latina, con miras a favorecer los intereses del capital minero canadiense. En este sentido, Francisco Ramírez (2006), quien era el presidente del ahora desaparecido Sindicato de Trabajadores de la Empresa Nacional Minera en Colombia, documentó la participación de ciDA en la reformulación del código minero colombiano en 2001. El nuevo código levantó restricciones en 
zonas abiertas a la minería. En Perú, cida invirtió 9.6 millones de dólares en el Proyecto de Reforma del Sector de Recursos Minerales 2002-2007 del país, oficialmente "para la provisión de asistencia técnica y trasferencia tecnológica al Ministerio de Energía y Minas del Perú para mejorar su capacidad de administrar más eficaz y eficientemente el sector minero y metalúrgico del país» (citado en Kuyek, 2006: 208). En otro ejemplo, poco después del golpe de Estado y posteriores elecciones que se realizaron en Honduras en 2009 y 2010, respectivamente, el embajador canadiense y el representante de CIDA en ese país arreglaron reuniones entre ejecutivos de empresas mineras de Canadá y el presidente recién electo, Porfirio Lobo Sosa, junto con algunos miembros de su gabinete (Gordon, 2011). Asimismo, se informó que los mismos diplomáticos sostuvieron conversaciones con ejecutivos mineros canadienses, con respecto a formas de influir en la redacción preliminar de la nueva legislación minera del país (Gordon, 2011), que finalmente fue aprobada a comienzos de 2013 a pesar de las protestas de la sociedad civil hondureña y organizaciones internacionales, como el Observatorio de Conflictos Mineros de América Latina.

\section{Desviar la mirada ante}

los enredos de la Bolsa de Valores de Toronto

No es una coincidencia que casi $60 \%$ de las compañías mineras del mundo se encuentran cotizando en la Bolsa de Valores de Toronto (TSX) o su afiliada menor la TSX Venture Exchange (Bolsa de Capital de Riesgo). Como se explica con detalle en el libro de Denault y Sacher (2012), Imperial Canada Inc., Canadá es un verdadero paraíso legal para las compañías mineras y, en particular, la TSX se destaca en el escenario mundial por estar sujeta a normas ambiguas y laxas. Se supone que la Comisión de Valores de Ontario regula a la tsx, sin embargo, en la práctica hace muy poco para controlar operaciones internas $y$ evitar que funcione como un casino. La incertidumbre asociada con la cuantificación de las reservas mineras coloca particularmente a esta industria en una 
situación muy propensa para la especulación financiera y es precisamente en ello en lo que está especializada la TSX: atraer capital especulativo. Denault y Sacher sostienen que esto brota del pasado colonial canadiense; el país se edificó sobre la base de la explotación y la especulación de recursos naturales, y los intereses de la élite en obtener beneficios de esta actividad ha determinado la legislación e instituciones financieras del país desde el siglo xix. Con la reestructuración neoliberal de la economía mundial durante los dos últimos decenios del siglo $\mathrm{xx}$, la TSx se ha constituido en el centro financiero para el capital minero transnacional. Entre 2007 y 2011, proporcionó a la industria minera 220 mil millones de dólares en financiación de capital, equivalente a más de un tercio del total mundial y dejando muy atrás, en segundo lugar, a la Casa de Bolsa de Londres, con $11.6 \%$ de ese mismo total (Denault y Sacher, 2012: 15-16).

\section{Beneficios fiscales}

Las compañías mineras canadienses se benefician de varios incentivos fiscales y subsidios en su país de origen. Programas federales como el Super Flow Through Share Program, el Accelerated Capital Cost Allowance y el Canadian Exploration Expenses permiten a las compañías mineras pagar muy pocos impuestos por sus actividades, aun cuando dichas operaciones dan la impresión de ser extremadamente rentables (Kuyek, 2007). Estos programas federales frecuentemente tienen como complemento programas de crédito fiscal para fomentar la exploración. Como ya se mencionó líneas arriba, el gobierno canadiense ha buscado exportar estos privilegios y beneficios alentando la reestructuración neoliberal de la legislación minera en América Latina. En este sentido, en Colombia - donde cida influyó en la formulación del código minero de 2001 - las regalías empresariales disminuyeron al pasar de $15 \%$ a tan sólo $0.4 \%$ (Ramírez, 2006: 181). Desde un ángulo distinto, el sector banquero canadiense ha desempeñado un papel clave para fomentar la creación de pa- 
raísos fiscales en el Caribe, donde grandes compañías mineras canadienses, como Goldcorp, han establecido subsidiarias para tener acceso a protección fiscal y legal para sus ganancias (Denault y Sacher, 2012: 9-10).

\section{Apoyo financiero directo}

El gobierno canadiense proporciona tres formas de apoyo financiero directo a las compañías mineras canadienses. Primera, hay montos significativos de participación en el capital social que provienen directamente de los planes de pensión administrados por los gobiernos federal y provinciales, incluyendo el Plan Canadiense de Pensiones (Canadian Pension Plan) y la Caja de Deposito e Inversiones (Caisse de Depots et Placements) en Quebec. El primero mantiene aproximadamente 2.5 mil millones de dólares de participación en compañías mineras que se comercian en la Tsx (Keenan, 2010: 31). Los fondos de retiro de los servidores públicos y docentes también representan aportaciones importantes. Segunda, las compañías mineras canadienses reciben apoyo financiero directo por sus operaciones en el exterior de la agencia federal denominada Desarrollo de las Exportaciones Canadienses (Export Development Canada, EDC), en forma de seguros y préstamos. En 2008, la EDC facilitó las actividades extractivas canadienses en América Latina con una aportación de cuatro mil millones de dólares (Keenan, 2010:31). La supervisión gubernamental y de la sociedad civil sobre el EDC es marginal, ya que tiene pocas obligaciones para hacer pública información sobre las actividades que financia (Kuyek, 2007: 208). En 2011, CiDA adoptó una tercera forma de apoyo financiero directo: el co-financiamiento de programas de responsabilidad social empresarial (RSE) en la vecindad de las operaciones mineras canadienses en los países en desarrollo. En esta línea, el gobierno canadiense comprometió 6.7 millones de dólares para proyectos piloto de RSE en Burkina Faso, Ghana y Perú, básicamente para compensar a los habitantes locales por la destrucción ambiental y el desasosiego social ocasionados por las actividades mineras 
altamente rentables de I AmGold, Rio Tinto Alcan y Barrick Gold, respectivamente. Además, CIDA comprometió 20 millones de dólares para una iniciativa de RSE en la región andina (Bolivia, Colombia y Perú, para ser específico) con el objetivo de «fortalecer la capacidad de los gobiernos locales y comunidades para que pongan en marcha proyectos de desarrollo sostenible» y para «mejorar el diálogo entre las comunidades y el sector privado» (CIDA, 2011) (la traducción de la cita es nuestra). Después de dos años de clamor público sobre este uso descarado del apoyo al desarrollo —o sea, recursos públicos que supuestamente están destinados a apoyar a los países en vías de desarrollopara respaldar los intereses del capital minero, en marzo de 2013, el gobierno derechista de Stephen Harper anunció que cida se integraría a la Secretaría de Relaciones con el Exterior, el cual sería rebautizado como la Secretaría de Relaciones Exteriores, Comercio y Desarrollo (Department of Foreign Affairs, Trade and Development).

\section{Rechazo a regular a las compañias}

mineras canadienses que operan en el exterior

La promoción y subsidio a la responsabilidad social empresarial (RSE) voluntaria es la otra cara de la moneda del rechazo del gobierno canadiense a regular las actividades de las compañías mineras canadienses en los países en desarrollo. A la luz de la evidencia acumulada en lo que se refiere a violaciones de derechos humanos y destrucción ambiental a gran escala, producto de las operaciones mineras canadienses en los países en desarrollo desde los años noventa, el gobierno federal creó, en 2005, la Comisión Permanente para las Relaciones con el Exterior y el Comercio Internacional (Standing Committee on Foreign Affairs and International Trade, SCFAIT) para escuchar el testimonio de los representantes de las comunidades afectadas. El informe publicado por la SCFAIT ese mismo año reconoció que las actividades mineras canadienses «[... ] en algunos países en desarrollo han tenido efectos adversos 
en las comunidades locales, especialmente donde las regulaciones que norman al sector minero y su impacto en el bienestar económico y social de los empleados y residentes locales, así como en el medio ambiente, son débiles o inexistentes, o no se cumplen», e incluso recomendó que el gobierno estableciera normas jurídicas claras para asegurar que las compañías mineras canadienses se hicieran responsables por los daños ambientales y las violaciones a los derechos humanos. No obstante, en lugar de tomar medidas específicas al respecto, el gobierno federal —liderado por el magnate Paul Martin, del Partido Liberal - estableció una serie de mesas redondas para que se sentaran a discutir sobre dichos asuntos los representantes de la industria minera, la academia, la sociedad civil, los sindicatos y el gobierno. En 2006, se llevaron a cabo seis sesiones de mesas redondas en Vancouver, Toronto, Calgary y Montreal, y en 2007 el Grupo Asesor (Advisory Group) para el proceso publicó un informe que incluyó varias recomendaciones bastante diluidas, donde las más importantes son el requisito de que las compañías extractivas operando en el exterior presentaran informes púbicos, para ser candidatas a recibir asistencia financiera pública y la creación de un «defensor del pueblo» (ombudsman) para que investigara las quejas por violaciones de derechos humanos ${ }^{1}$ Dos años después, el gobierno Conservador de Stephen Harper respondió con la presentación de un documento titulado «Edificando la ventaja canadiense: una estrategia de responsabilidad social empresarial (RSE) para el sector extractivo internacional canadiense» (Anónimo, 2009), que ignoró aquellas modestas recomendaciones y sólo propuso «directrices» voluntarias de RSE para las compañías extractivas canadienses operando en el extranjero. En lugar de un ombudsman independiente, el gobierno creó un «asesor legal» en RSE, que sólo puede revisar las prácticas de RSE de una empresa siempre y

/1/ Véase Coumans (2010) y Keenan (2010) para descripciones más detalladas de este proceso. Ambos autores proporcionan una «perspectiva desde dentro» en tanto que formaron parte del grupo asesor para las discusiones celebradas en las mesas redondas, en 2006. 
cuando dicha empresa consienta en ello y, en cualquier caso, dicho asesor no puede emitir ninguna recomendación vinculante.

En un suceso paralelo, un mes previo a que el gobierno de Harper presentara el documento «Edificando la ventaja canadiense», John McKay — parlamentario liberal - introdujo en la Cámara de los Comunes de Canadá una «propuesta de ley para los integrantes privados»: Bill C-300. Esta propuesta de ley contenía normatividad relativamente tímida dirigida a las compañías extractivas canadienses operando en el extranjero, que giraba en torno a la creación de mecanismos para investigar quejas de las comunidades que se vieran afectadas negativamente. En este esquema, las compañías culpables de violar derechos humanos o provocar daños ambientales mayores correrían el riesgo de dejar de recibir los subsidios del gobierno canadiense. La propuesta de ley no contenía medidas para llevar ante la justicia a los CEO ni para forzar a las compañías a que repararan daños. De todos modos, no prosperó en la Cámara de los Comunes. El 27 de octubre de 2010 fue rechazada por un voto dividido de 140 a 134; rechazada por todos los parlamentarios del Partido Conservador Progresista de Harper, con la excepción de tres, mientras que 17 miembros del Partido Liberal y del Nuevo Partido Democrático se abstuvieron de votar, incluyendo el dirigente del Partido Liberal en ese momento, el académico Michael Ignatieff, autor de Empire Lite. ${ }^{2}$ En cualquier caso, después de varios años de discusiones y deliberaciones, el resultado final fue mantener el statu quo: las compañías extractivas canadienses no tienen que rendir cuentas sobre sus actividades en el extranjero.

\section{Promoción diplomática de la RSE}

En lugar de establecer un marco regulatorio, el gobierno canadiense ha intensificado su campaña de relaciones públicas en respaldo de la RSE voluntaria.

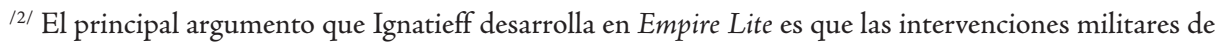
Estados Unidos son una carga moral necesaria para la única súper potencia. En sus propias palabras: 
Por ejemplo, la embajada canadiense en México fue anfitriona de un seminario concerniente a la RSE en enero de 2011, con el objetivo de «informar y capacitar a los directivos, coordinadores de relaciones con las comunidades y gerentes de empresas del sector minero, sobre la importancia y necesidad actual de ser socialmente responsables y mejorar la relación con las comunidades donde las empresas mineras tienen operaciones» (Anónimo, 2010). Seminarios similares se llevaron a cabo en las embajadas canadienses en Perú y Ecuador en 2010. En el mismo tenor, Marketa Evans, la jefa de la Oficina del Asesor para la RSE del Sector Extractivo (Office of the Extractive Sector CSR Counsellor), pasó volando a todas partes del mundo los dos primeros años en su puesto. Su objetivo era promover la RSE de las industrias extractivas canadienses: 47 viajes en total a África, América Latina, Washington y ciudades en Canadá. Aun cuando la Oficina del Asesor no había mediado una sola queja en contra de una compañía minera canadiense - nuevamente, no podría realizarlo sin el consentimiento de la compañía en cuestión-, ya había erogado 1.1 millones de dólares entre marzo de 2010 y febrero de 2012 por concepto de gastos en viajes, reuniones, talleres, informes, entretenimiento (Weston, 2012). Otras medidas de relaciones públicas que llevó a cabo el gobierno canadiense para promover la RSE se mencionan en el boletín electrónico de la RSE (Corporate Social Responsibility E-Bulletin), disponible en el sitio web de la Secretaría de Relaciones Exteriores y Comercio Internacional de Canadá (Department of Foreign Affairs and International Trade, DFAIT).

\section{¿ESTO CONSTITUYE IMPERIALISMO?}

En el análisis clásico que Lenin hizo del imperialismo a comienzos del siglo xx, sostiene que el imperialismo es más que un simple cambio de la política exterior

«A nadie le gusta los imperios, sin embargo, hay algunos problemas para los cuales sólo hay soluciones imperiales» (epígrafe en la portada de Ignatieff, 2006). 
de los países «avanzados», refleja una evolución en las relaciones de producción del sistema capitalista, específicamente hacia una etapa monopólica del capitalismo. Entonces, de acuerdo con esta aseveración definitoria, el asunto está en establecer si los mecanismos descritos en la sección anterior - a los que recurre el gobierno canadiense para promover los intereses de las compañías mineras canadienses que operan en América Latina- únicamente representan un cambio en la política de una potencia «sub-imperial» o si además reflejan una etapa cualitativamente diferente en el sistema capitalista mundial.

En la época de Lenin, al imperialismo se caracterizaba por el dominio de los monopolios y el capital financiero, la pronunciada importancia de la exportación de capital y la división territorial del planeta entre las mayores potencias capitalistas (Lenin, 1999). El imperialismo contemporáneo muestra continuidades y rupturas con ese periodo clásico. Surgió de la etapa monopólica del capitalismo previa, después de dos guerras mundiales imperialistas y la así denominada «época dorada del capitalismo». En el contexto de la Guerra Fría, los países en África y el sudeste asiático obtuvieron su independencia y durante el periodo posterior a la Segunda Guerra Mundial los países desarrollados -y hasta cierto punto los países industrializados en el Sur mundial - establecieron pactos sociales fordistas entre el capital y la fuerza de trabajo sindicalizada, y edificaron diferentes versiones del Estado universal de bienestar (Esping-Andersen, 1990). En el contexto de la crisis de sobre producción de los años setenta y la consiguiente reestructuración de la economía mundial de acuerdo con los principios del neoliberalismo, dio inicio una nueva etapa del capitalismo, donde el proceso de «acumulación por desposesión» desempeña un papel toral (Harvey, 2004). Entonces, hablando en términos generales, podemos observar dos etapas en la evolución del sistema capitalista mundial desde la Segunda Guerra Mundial, cada una de ellas con su forma distintiva de imperialismo. ${ }^{3}$

13/ Panitch y Gindin (2003) critican el enfoque «etapista» que se muestra en el pensamiento clásico relativo al imperialismo de Hobson a Lenin. En las palabras de aquellos autores, «la izquierda nece- 
Al igual que la etapa clásica del imperialismo, la última etapa neoliberal está caracterizada por monopolios - o, para ser más preciso, por oligopolios-que dominan sectores importantes de la economía, incluyendo las industrias extractivas. Se ha dado una «financialización de la economía» en lo que se refiere al peso creciente de capital especulativo ficticio y la exportación de capital en la forma de inversión extranjera directa, como lo muestra un marcado incremento desde el decenio de 1980. Por otro lado, las naciones del centro ya no buscan ejercer directamente el control administrativo sobre territorios extranjeros para explotación exclusiva. El capital se ha «trasnacionalizado» no sólo con respecto a su creciente movilidad transfronteriza, sino en tanto que se complica la identificación de su origen nacional (Robinson, 2010). Al mismo tiempo, la dimensión militar de las rivalidades imperialistas ha quedado en gran medida opacada por el surgimiento de una única súper potencia: Estados Unidos, que recurre a su poder militar para disciplinar Estados rebeldes e imponer la agenda neoliberal.

En este contexto, se lleva a cabo una competencia económica entre Estados y entre regiones — a diferencia de las «rivalidades» imperialistas y militares de hace un siglo- en torno a algunos temas comunes, incluyendo la competencia que hacen a Estados Unidos la Unión Europea y Japón desde el periodo posterior a la Segunda Guerra Mundial, y más recientemente el surgimiento de los BRIC (Brasil, Rusia, India y China). En particular, algunos

sita una nueva teoría del imperialismo, una que trascienda las limitaciones de la vieja teoría "etapista" marxista de rivalidad inter-imperialista y permita una apreciación plena de los factores históricos que han llevado a la formación de un único imperio informal estadounidense en la era neoliberal» (Panitch y Gindin, 2003: 4; la traducción es nuestra). Sin embargo, en su propia revisión de estos factores históricos, surgen distintas etapas: la reconstrucción del orden capitalista mundial en el periodo posterior a la Segunda Guerra Mundial y la subsecuente reconstrucción del imperio estadounidense en la era neoliberal. Entonces, si bien es cierto que «no es posible reducir el imperialismo a una explicación económica» (Panitch y Gindin, 2003: 6) y que la etapa del capitalismo que Lenin consideró ser la más alta fue de hecho una fase relativamente temprana, sigue siendo útil distinguir entre diferentes «etapas» en la evolución del sistema capitalista para entender las dinámicas cambiantes del imperialismo. 
ven en China una amenaza a la hegemonía de Estados Unidos en el ámbito mundial, ${ }^{4}$ especialmente en el contexto de la crisis económica más reciente en Estados Unidos y Europa. En la esfera económica, la reprimarización de las economías latinoamericanas está vinculada al incremento en la demanda de materias primas debido al robusto crecimiento económico chino y su peso demográfico. Las empresas chinas han comenzado a invertir fuertemente en las industrias extractivas de América del Sur y sus bienes manufacturados baratos compiten con los producidos en México y América Central.

Estos procesos han coincidido con el surgimiento de gobiernos progresistas en América del Sur, la así denominada «ola rosa» de los gobiernos posneoliberales, ninguno de los cuales puede ser considerado como socialista de acuerdo con Petras y Veltmeyer (2011), con la posible excepción de Venezuela. No obstante, a lo largo de los últimos 10 años la ideología neoliberal ha perdido mucha de su hegemonía en la región, por lo menos a nivel discursivo. Además, los gobiernos progresistas en Argentina, Bolivia, Brasil, Ecuador y Uruguay se las han arreglado para conseguir un mejor acuerdo con el capital extractivo extranjero; dicho acuerdo permite a los Estados recibir una pieza más grande del pastel. Ésta es la esencia del tan discutido «nuevo extractivismo» en América del Sur (Gudynas, 2010). En estos países también grupos indígenas y campesinos han hecho alianzas con organizaciones de la sociedad civil para formar movimientos de resistencia ante la minería (Bebbington, 2011). En lugares como Bolivia y Ecuador, donde compañías mineras extranjeras operan minas a cielo abierto, altamente destructivas en términos ecológicos, estos movimientos llaman la atención a la laguna que existe entre el discurso del «vivir bien»o «buen vivir» y la práctica de permitir que dichas compañías violen la «madre tierra» para enriquecer a los grandes accionistas y llenar las arcas públicas (Svampa, 2011).

/4/ Para una opinión contraria con respecto a China y la amenaza que representa para la hegemonía de Estados Unidos, véase Amhad (2003) y Panitch y Gindin (2003). 
Desde otro ángulo, Robinson $(2008,2010)$ sugiere que las rivalidades entre Estados han quedado en segundo plano en la medida que el Estado se adapta para manejar una economía liberalizada dominada por los intereses del capital transnacional. En sus palabras, «la transnacionalización del capital transnacionaliza la base sobre la cual los funcionarios del Estado y la élite política realizan su producción» (Robinson, 2010: 68). Esto no quiere decir que el capital ya no necesita al Estado para crear y mantener las condiciones necesarias para su expansión, sino más bien «el sistema de Estados nacionales, compuesto de unidades discretas interactuando entre sí, ha dejado de ser el principio organizador del desarrollo capitalista» (Robinson, 2010: 62). Este autor sostiene que la reestructuración neoliberal de la economía mundial, encabezada por Estados Unidos, no ha privilegiado los intereses de las corporaciones estadounidenses (que según él, resultan difíciles de definir como tal debido a que tiene fuentes de capital, oficinas y operaciones en todas partes del mundo), sino a intereses del capital transnacional en todo el mundo, incluso en el Sur global. En esta línea, el autor hace notar que los programas de ajuste estructural, aplicados después de la crisis de la deuda a principios de los años ochenta, no resultaron en disposiciones especiales para el capital estadounidense. Esto ayudaría a explicar por qué el capital canadiense ha podido llegar a dominar en el sector minero de América Latina.

No cabe duda que Robinson ha aportado elementos importantes al debate actual sobre el imperialismo, no obstante, su análisis tiende a pasar por alto las formas en que el Estado sigue desempeñando un papel central para facilitar la acumulación de capital al favorecer al capital nacional. Contrario a la afirmación según la cual ya no es posible identificar con claridad la base nacional de la mayoría de las corporaciones, Gordon sostiene que «la mayor parte de las oficinas centrales de las corporaciones multinacionales se encuentra en un país específico, cuenta con una red de accionistas menores o mayores ahí y se apoya en su Estado particular para facilitar su expansión mundial» (Gordon, 2010: 52). La expansión de las actividades de las compañías mineras canadienses apoya esta afirmación. Como ya se dijo antes, además de los 
accionistas canadienses privados de las compañías mineras con sedes en el mismo país, los planes de pensión administrados por el gobierno canadiense equivalen a miles de millones de dólares en acciones de esas compañías. Además, los fundadores y los CEO de las grandes compañías mineras canadienses que operan en América Latina son ciudadanos canadienses. Al mismo tiempo, los mecanismos esbozados arriba ilustran una estrategia de apoyo agresiva que descansa en la asimetría de las relaciones de poder entre los países del centro de la economía mundial y los que están en la periferia, una división que corresponde básicamente al Norte y el Sur.

Por supuesto, el imperialismo contemporáneo, que no descansa en el control administrativo directo de territorios extranjeros para edificar «imperios formales», requiere la colaboración de agentes y agencias en los países del Sur. Para empezar, una clase política local proclive a la agenda neoliberal debe llevar a cabo las reformas estructurales necesarias para facilitar la penetración del capital extranjero. Donde esta proclividad no predomina, el Fmi y el Banco Mundial ejercen presiones durante momentos de crisis. En otro nivel, las agencias públicas encargadas de hacer cumplir la legislación ambiental tienen que aportar legitimidad a las operaciones mineras, aun ante la destrucción ambiental de proporciones monumentales y la violación de derechos humanos. La experiencia de la mina San Xavier de New Gold, en San Luis Potosí, México, es un claro ejemplo. ${ }^{5}$

${ }^{15 /}$ A partir de los años ochenta, se fortalecieron las políticas ambientales mexicanas, por lo menos en el papel, para responder a las críticas en torno a la reestructuración neoliberal. De esta manera, se estableció el marco legal para las acciones desarrolladas por el movimiento local de resistencia en San Luis Potosí, que llevó a que el Tribunal Federal de Justicia Fiscal y Administrativa anulara la autorización que la Secretaría del Medio Ambiente y Recursos Naturales (semarnat) había otorgado a New Gold, con respecto a su evaluación de impacto ambiental. No obstante, New Gold ha logrado continuar con sus actividades extractivistas a cielo abierto, con el apoyo de los altos funcionarios de la semarnat. Así, a final de cuentas, en México y en otras partes, el imperativo de la acumulación de capital tiene precedencia sobre las consideraciones ambientales y también sobre la autodeterminación de las comunidades locales. 
Finalmente, donde surgen movimientos de resistencia, como ha sido el caso a lo largo de América Latina, a la policía y al ejército en los países anfitriones les toca el trabajo sucio de intimidar a los disidentes y practicar formas violentas de represión, en ocasiones dejando lo más sucio de dichas acciones a fuerzas paramilitares. Desde 2010, por lo menos nueve opositores a las operaciones mineras canadienses en América Latina han sido asesinados, cinco en México, tres en El Salvador y uno en Guatemala. Cientos más han recibido golpizas y han sido arrestados durante manifestaciones de protesta pacíficas.

De esta manera, las mineras canadienses en América Latina reflejan una estrategia imperialista de «acumulación por desposesión» (Gordon y Webber, 2008). En otras palabras, las ganancias de las compañías mineras canadienses se realizan con altos costos para comunidades locales, campesinos y grupos indígenas, que son desposeídos de sus recursos naturales y paisajes culturales con el fin de abrir camino a las actividades mineras a gran escala. Sin duda, y debido a que las técnicas mineras modernas son altamente destructivas en términos ambientales, tienden a desplazar otras formas de explotación de recursos naturales, incluyendo la agricultura y la ganadería a pequeña escala. Esto se debe a que después de 500 años de conquista y colonialismo, los yacimientos de alta ley en América Latina están agotados; ahora las empresas mineras tienen que procesar enormes cantidades de mineral tan sólo para extraer ínfimas cantidades de metales preciosos, que son lo que buscan las compañías mineras canadienses. ${ }^{6}$ Ello implica recurrir a las minas a cielo abierto y las técnicas de separación por lixiviación que destruyen totalmente la tierra bajo la cual se encuentran los minerales, consumen enormes cantidades de agua y emplean cianuro y otras sustancias altamente tóxicas. De esta manera, el

16/ En el siglo XIX, procesar una tonelada de mineral producía en promedio 20 gramos de oro. Hoy en día, para obtener 20 gramos de oro, las compañías mineras tienen que procesar en promedio 133 toneladas de mineral. De igual manera, para extraer los mismos 20 gramos de oro, la cantidad de agua requerida se ha incrementado al pasar de 1,400 litros a 186,600 litros en los últimos 100 años (Garibay, 2010: 134). 
medio ambiente queda devastado, ocasionando daños a la salud de los habitantes locales y destruyendo los medios de vida tradicionales, sin mencionar la destrucción de los sitios sagrados de los grupos indígenas (Earthworks y Oxfam America, 2004).

Todo ello contribuye a una forma de «acumulación por desposesión», esto es, la usurpación de los recursos naturales utilizados por los habitantes locales - muchos de los cuales, en el contexto de América Latina, son campesinos semiproletarizados que producen para la auto subsistencia y mercados locales- para abrir espacio para las compañías mineras. Además, el arribo de estas compañías es un acicate al proceso de proletarización en la medida que separa a los campesinos y grupos indígenas de sus medios de producción, sea por medio de la apropiación directa de sus tierras o agotando y contaminando sus escazas fuentes de agua. Los campesinos desplazados tienen que competir por el empleo temporal poco calificado que proporcionan las minas durante la etapa de inicio de su operación o emigrar a las ciudades para engrosar las filas de pobres que habitan en los tugurios urbanos. La emigración internacional también es una opción para algunos, o cuando menos era una opción, con un conjunto de costos y riesgos asociados. Como consecuencia de la más reciente crisis económica en Estados Unidos y Europa, hay menos oportunidades de empleo para los migrantes, por lo que han retornado en masa a México y otros lugares.

Para que el concepto de «acumulación por desposesión» tenga sentido en este análisis, tenemos que reconocer que el trabajo no es la única fuente de riqueza. Como señaló Marx, citando a William Petty, «el trabajo es el padre de la riqueza y la tierra, su madre». En otras palabras, el sitio de una mina no es sólo el espacio territorial donde se crea plusvalía a través de la súper explotación de los mineros; es el lugar donde se destripa la madre tierra de los recursos naturales escasos y no renovables. Mientras aquéllos que exaltan las virtudes del crecimiento económico vía la industrialización podrían justificar formas relativamente benignas de minería para producir metales básicos y ferosos, es imposible justificar la destrucción que se permite a las compañías privadas para extraer metales preciosos que se utilizan en su gran mayoría 
para producir joyería y artículos decorativos para la gente rica y la clase media ascendente o para producir lingotes que sirven como un refugio para el capital especulativo en periodos de crisis. ${ }^{7}$

La privatización de reservas minerales y compañías mineras de propiedad pública representa otra forma de «acumulación por desposesión». De acuerdo con Harvey (2004), que fue quien popularizara el término, el proceso comparte mucho con el de «acumulación originaria» $\mathrm{o}$ «acumulación primitiva» descrita por Marx en el primer volumen de El Capital. Incluye, entre otros procesos:

La mercantilización y privatización de la tierra y la expulsión forzosa de las poblaciones campesinas; la conversión de diversas formas de derechos de propiedad — común, colectiva, estatal— en derechos de propiedad exclusivos; la supresión del derecho a los bienes comunes; la transformación de la fuerza de trabajo en mercancía y la supresión de formas alternativas (indígenas) de producción y consumo; los procesos coloniales, neocoloniales e imperiales de apropiación de activos, incluyendo los recursos naturales (2004: 113).

Mientras Marx vio estos procesos únicamente durante las etapas iniciales del capitalismo, Harvey, siguiendo a Rosa Luxemburgo, sostiene que se les puede observar a lo largo de la historia del capitalismo. Asimismo, este autor sugiere que han sido especialmente sobresalientes en los últimos 30 años, en el contexto de los ajustes estructurales encabezados por el FMi y el Banco Mundial. La explicación que proporciona Harvey de estos procesos de privatización ajusta muy bien con la forma en que el sector minero se ha venido reestructurando en México y Colombia, donde el modelo neoliberal se ha manifestado en formas ortodoxas.

${ }^{17 /}$ Cerca de $50 \%$ del oro que se produce se utiliza para elaborar joyería, 40\% se utiliza para producir monedas o lingotes de oro para inversión especulativa y 10\% se utiliza en la industria (Soos, 2011). 


\section{Conclusión}

El ascenso de las compañías mineras canadienses y su dominio mundial pueden explicarse en gran medida por el respaldo que han recibido de su gobierno en el contexto de la reestructuración neoliberal de la economía mundial. Como se detalló en la primera parte de este artículo, el gobierno canadiense ha ayudado a que las compañías mineras canadienses obtengan acceso a los recursos minerales en América Latina y en otros lugares mediante el impulso de reformas neoliberales, la intervención en la reformulación de la legislación minera, la desregulación de la Bolsa de Valores de Toronto, las exenciones fiscales, los subsidios directos y el apoyo diplomático a las compañías mineras canadienses que operan en el extranjero, rehusándose a regularlas en sus operaciones fuera del país. Estos mecanismos en sí no constituyen imperialismo si, al igual que Foster (2003), seguimos a Lenin en su definición de imperialismo como «no simplemente una política sino una realidad sistemática que surge de la naturaleza misma del desarrollo capitalista» (énfasis en el original). Sin embargo, sí reflejan las estrategias imperialistas de una potencia media que ha contribuido a dar forma a la evolución del sistema capitalista mundial hacia los principios de libre comercio, privatización y desregulación. Además, estos mecanismos han allanado el camino para que las compañías mineras canadienses accedan a reservas mineras de bajo costo y mano de obra barata en el Sur mundial, donde las regulaciones son laxas o no se hacen cumplir, permitiendo la externalización de los costos ambientales y sociales que en su mayoría pagan las poblaciones rurales pobres que viven cerca de las minas.

\section{REFERENCIAS}

Amhad, Aijaz (2003), «Imperialism of Our Time», en Leo Panitch y Colin Leys (editores), The New Imperial Challenge, Socialist Register 2004, Halifax, Fernwood Publishing. 
Anónimo (2009), «Building the Canadian Advantage: A Corporate Social Responsibility (CSR) Strategy for the Canadian International Extractive Sector», en 〈http://www.international.gc.ca/trade-agreementsaccords-commerciaux/topics-domaines/other-autre/csr-strat-rse. aspx >.

(2010), «Impulsarán la responsabilidad social de la industria minera», El Financiero, en 〈http://noticiasmineras.mining.com/2010/07/23/impulsaran-la-responsabilidad-social-de-la-industria-minera/> (consultado el 15 de enero de 2013).

Bebbington, Anthony (editor) (2011), Minería, movimientos sociales y respuestas campesinas. Una ecología política de transformaciones territoriales, Lima, Instituto de Estudios Peruanos y Centro Peruano de Estudios Sociales.

CIDA (Canadian International Development Agency) (2011), «Minister Oda announces initiatives to increase the benefits of natural resource management for people in Africa and South America», Foreign Affairs, Trade and Development Canada, en 〈http://www.acdi-cida.gc.ca/acdi-cida/ ACDI-CIDA.nsf/eng/CAR-929105317-KGD >.

CIDP (Canadian International Development Platform) (sin fecha), «Canadian Mining Investments in Latin America», en 〈http://cidpnsi.ca/blog/ portfolio/canadian-mining-investments-in-latin-america/> (consultado el 27 de marzo de 2013).

Coumans, Catherine (2010), «Alternative Accountability Mechanisms and Mining: The Problems of Effective Impunity, Human Rights, and Agency», Canadian Journal of Development Studies, volumen 30, número 1-2. Denault, Alain y William Sacher (2012), Imperial Canada Inc. Legal Haven of Choice for the World's Mining Industries, Vancouver, Talonbooks.

Eart hworks y Oxfam America (2004), Dirty Metals. Mining, Communities and the Enivronment, Washington, Earthworks and Oxfam America.

Esping-Andersen, Gøsta (1990), The Three Worlds of Welfare Capitalism, Princeton, Princeton University Press. 
Foster, John Bellamy (2003), «The New Age of Imperialism», Montbly Review, volumen 55, número 3.

Garibay, Claudio (2010), «Paisajes de acumulación minera por desposesión campesina en el México actual», en Gian Carlo Delgado Ramos (coordinador), Ecología política de la Minería en América Latina. Aspectos socioeconómicos, legales y ambientales de la mega minería, México, unam, Centro de Investigaciones Interdisciplinarias en Ciencias y Humanidades.

Gordon, Todd (2010), Imperialist Canada, Winnipeg, Arbeiter Ring Publishing. (2011), «Military Coups are Good for Canadian Business: the Canada-Honduras Free Trade Agreement», The Bullet, en 〈http://www. newsocialist.org/index.php?option $=$ com_content $\&$ view $=$ article $\&$ id $=$ 398:military-coups-are-good-for-canadian-business-the-canadahonduras-free-trade-agreement $-\&$ catid $=51$ : analysis $\&$ Itemid $=98$ >

Gordon, Todd y Jeffery Webber (2008), «Imperialism and Resistance: Canadian mining companies in Latin America», Third World Quarterly, volumen 29 , número 1 .

Gudynas, Eduardo (2010), «El nuevo extractivismo del siglo xxi. Diez tesis sobre el extractivismo bajo el progresismo sudamericano actual», Memoria, número $242 / 243$.

Harvey, David (2004), «El Nuevo imperialismo: acumulación por desposesión», Socialist Register, en 〈http://bibliotecavirtual.clacso.org.ar/ar/ libros/social/harvey.pdf>.

Ignatieff, Michael (2006), Empire Lite, Toronto, Penguin Group.

Keenan, Mary (2010), «Canadian Mining Still Unaccountable», nacla report on the Americas, mayo-junio, en 〈http://nacla.org/sites/default/ files/A043030031_8.pdf> (consultado el 12 de febrero de 2013).

Kuyek, Joan (2006), «Legitimating Plunder. Canadian Mining Companies and Corporate Social Responsibility», en Liisa North, Timothy David Clark y Viviana Patroni (editores), Community Rights and Corporate Responsibility. Canadian Mining and Oil Companies in Latin America, Toronto, Between the Lines. 
(2007), Mining Investors. Understanding the legal structure of a mining company and identifying its management, shareholders and relationship with the financial markets, en 〈http://www.miningwatch.ca/sites/miningwatch.ca/ files/Mining_Investors.pdf> (consultado el 19 de febrero de 2013).

Lenin, Vladimir (1999), Imperialism. The Highest Stage of Capitalism, Sydney, Resistance Books.

McNally, David (2006), «Canada and Empire», New Socialist. Ideas for Radical Change. Special Issue on Canada and Empire, número 54.

Mining Association of Canada (2011), «Facts and Figures of the Canadian Mining Industry», en 〈http://www.mining.ca/www/media_lib/MAC_ Documents/F\&F 2011-English.pdf> (consultado en mayo de 2012).

Panitch, Leo y Sam Gindin (2003), «Global Capitalism and American Empire», en Leo Panitch y Colin Leys (editores), The New Imperial Challenge, Socialist Register 2004, Halifax, Fernwood Publishing.

Petras, James y Henry Veltmeyer (2011), «Rethinking Imperialist Theory and us Imperialism in Latin America», Historia Actual Online, número 26. Ramírez, Francisco (2006), «State Terrorism and the Dirty Business of Mining in Colombia», en Liisa North, Timothy David Clark y Viviana Patroni (editores), Community Rights and Corporate Responsibility. Canadian Mining and Oil Companies in Latin America, Toronto, Between the Lines.

Robinson, William (2008), Latin America and Global Capitalism: A Critical Globalization Perspective, Baltimore, John Hopkins University.

(2010), «Beyond the theory of imperialism. Global capitalism and the transnational state», en Alexander Ancevas (editores), Marxism and World Politics: Contensting Global Capitalism, Nueva York, Routledge.

Soos, Andy (2011), «Gold Mining Boom Increasing Mercury Pollution Risk», en 〈http://oilprice.com/Metals/Gold/Gold-Mining-Boom-Increasing-Mercury-Pollution-Risk.html> (consultado el 6 de junio de 2012).

Svampa, Maristella (2011), «Modelo de desarrollo y cuestión ambiental en América Latina. Categorías y escenarios en disputa», en Fernanda Wan- 
derley (coordinador), El desarrollo en cuestión: Reflexiones desde América Latina, La Paz, Cides, umsa, Oxfam.

Weston, Greg (2012), «Federal mining agency can't find work», Свс News, en 〈http://www.cbc.ca/news/canada/story/2012/02/19/canadian-mining-mediation-agency-spending,html> (consultado el 21 de febrero de 2012).

Wood, Ellen Meiksins (2003), Empire of Capital, Nueva York, Verso. 
